\section{(1)}

CrossMark

\title{
Right heart catheterisation is still a fundamental part of the follow-up assessment of pulmonary arterial hypertension
}

\author{
Marc Humbert (10) $1,2,3$ and Jason Weatherald (10) 4,5
}

Affiliations: 'Université Paris-Sud, Faculté de Médecine, Université Paris-Saclay, Le Kremlin-Bicêtre, France. ${ }^{2}$ Service de Pneumologie, Hôpital Bicêtre, AP-HP, Le Kremlin-Bicêtre, France. ${ }^{3}$ INSERM UMR S 999, Hôpital Marie Lannelongue, Le Plessis Robinson, France. "University of Calgary, Dept of Medicine, Division of Respirology, Calgary, AB, Canada. ${ }^{5}$ Libin Cardiovascular Institute of Alberta, University of Calgary, Calgary, AB, Canada.

Correspondence: Marc Humbert, Université Paris-Sud, Centre de Référence de l'Hypertension Pulmonaire, Service de Pneumologie, Hôpital Bicêtre, 78, Rue du général Leclerc, 94270 Le Kremlin-Bicêtre, France. E-mail: marc.humbertवaphp.fr

@ERSpublications

Right heart catheterisation is still a fundamental part of the follow-up assessment of pulmonary arterial hypertension http://ow.ly/BUUi30kbbM5

Cite this article as: Humbert M, Weatherald J. Right heart catheterisation is still a fundamental part of the follow-up assessment of pulmonary arterial hypertension. Eur Respir J 2018; 52: 1800738 [https://doi.org/ 10.1183/13993003.00738-2018].

For patients with pulmonary arterial hypertension (PAH), the most recent European guidelines state that right heart catheterisation (RHC) is mandatory for confirming the diagnosis of PAH, and that RHC should be considered 3-6 months after therapy changes and in patients who experience clinical deterioration $[1,2]$. The guidelines also mention that some centres perform RHC at regular intervals during follow-up $[1,2]$. However, many centres across the world do not routinely monitor invasive haemodynamic variables during follow-up, for a variety of potential reasons including the invasive nature of the test, cost or availability. We argue that, based on current data, RHC is still an indispensable component of the clinical management and follow-up of PAH patients in the current treatment era.

The goal of treatment in PAH is to achieve or maintain a low-risk clinical profile, which can be defined by the accumulation of an increasing number of low-risk features [1,3-5]. A multidimensional risk stratification tool that includes clinical variables and markers of right ventricular function may classify patients at low $(<5 \%)$, intermediate $(5-10 \%)$ and high $(>10 \%)$ risk of death within the following year [ 1 , 2]. Several recent studies in contemporary $\mathrm{PAH}$ populations have helped validate this approach in assessing treatment responses and prognostication [3-5]. In the French registry, 1017 patients with PAH who underwent RHC within the first year of treatment were risk stratified by the number of low-risk criteria present: cardiac index $\geqslant 2.5 \mathrm{~L} \cdot \mathrm{min}^{-1} \cdot \mathrm{m}^{-2}$, right atrial pressire $<8 \mathrm{mmHg}$, New York Heart Association (NYHA) functional class I or II, and 6-min walk distance (6MWD) $>440 \mathrm{~m}$ [3]. The haemodynamic low-risk criteria at the time of follow-up RHC were independently associated with long-term outcomes; therefore, follow-up RHC added value beyond the noninvasive variables. These results were consistent with a previous study by Nickel et al. [6] and a haemodynamic substudy of the SERAPHIN randomised controlled trial comparing macitentan to placebo, where having a cardiac index 
$\geqslant 2.5 \mathrm{~L} \cdot \mathrm{min}^{-1} \cdot \mathrm{m}^{-2}$ after 6 months of treatment was a useful predictor of disease progression and morbidity [7]. Even in patients who achieve multiple low-risk clinical criteria, including a cardiac index $\geqslant 2.5 \mathrm{~L} \cdot \mathrm{min}^{-1} \cdot \mathrm{m}^{-2}$, there is additional value in quantifying the stroke volume index (SVI) from a follow-up RHC, independent of noninvasive clinical and demographic prognostic factors [8]. We found that patients with a SVI $<38 \mathrm{~mL} \cdot \mathrm{m}^{-2}$ had worse long-term outcomes even when multiple low-risk criteria were present, which highlights the power of RHC-derived measurements in describing right ventricular function as guidance in treatment decision making and prognostication $[8,9]$.

While it may be true that a noninvasive risk stratification can identify patients at low risk of short- and long-term adverse events, haemodynamic assessment is still likely to be required for the majority of PAH patients who do not meet the noninvasive low-risk criteria. In the study from the French registry by BouCLY et al. [3], a subgroup of 603 patients with brain natriuretic peptide (BNP) or N-terminal (NT)-pro-BNP measurements allowed the identification of a very low-risk subgroup defined by the presence of normal BNP $\left(<50 \mathrm{ng} \cdot \mathrm{L}^{-1}\right)$ or NT-pro-BNP $\left(<300 \mathrm{ng} \cdot \mathrm{L}^{-1}\right)$, NYHA functional class I or II, and $6 \mathrm{MWD}>440 \mathrm{~m}$. Patients with all three noninvasive low-risk criteria had a $100 \%, 99 \%$ and $97 \%$ survival at 2, 3 and 5 years, respectively. HoEPER et al. [10] recently confirmed the utility of this noninvasive method of identifying a very low-risk group in the COMPERA registry, with 1-, 3-, and 5-year survival rates of $100 \%, 100 \%$ and $95 \%$, respectively. However, only a small minority of patients meets all three of these noninvasive criteria during follow-up (9\% in the COMPERA study and $19 \%$ in the French study). Thus, most patients do not meet the noninvasive "screening" for low risk and should have the gold standard test to better elucidate the state of right ventricular function and pulmonary haemodynamics. Noninvasive assessment of right ventricular function, including SVI, with magnetic resonance imaging (MRI) has great prognostic utility in PAH $[11,12]$ and deserves further research, but the extent of the supportive evidence, its availability for serial assessments, and clinician experience using MRI for guiding clinical decision making is less than with RHC at the current time. A final point about the utility of RHC pertains to the shifting demographics of PAH patients in recent decades with an increasing proportion of elderly patients and a greater burden of comorbidities [13-16]. Few PAH patients over 65 years old ever achieved a low-risk profile in a recent study from Sweden [16]. Haemodynamics could be particularly useful in elderly patients since symptoms and exercise capacity may be related to comorbid diseases. It is likely and even probable that some of these older patients diagnosed with pre-capillary PAH have occult left heart disease or a combined pre- and post-capillary pulmonary hypertension that could manifest during periodic haemodynamic re-evaluation $[17,18]$.

We can be reassured that RHC is a safe procedure in experienced hands. Hoeper et al. [19] reviewed 7218 procedures and found with an overall adverse event rate of $0.8-1.3 \%$. The majority of RHC complications were mild to moderate in intensity and resolved either spontaneously or with direct management. There was only one patient with nonfatal permanent disability related to pain from a groin haematoma and there were four total fatalities, two of which were likely related to the RHC itself (one related to pulmonary artery rupture and one related to pulmonary angiography causing pulmonary artery rupture and haemorrhage). Thus, RHC has an exceedingly low risk of death $(0.055 \%)$ and permanent disability $(0.01 \%)[19]$.

There is a relative wealth of data derived from numerous studies that comprised thousands of PAH patients supporting the prognostic importance of haemodynamics in comparison to the relatively few numbers of studies and patients with biomarkers, MRI or echocardiographic measurements used for risk assessment. Thus, the utility of RHC for routine follow-up is supported by the sheer size and weight of the evidence available at the current time. We contend that while routine RHC may not be necessary during follow-up for a small proportion of patients who meet noninvasive low-risk criteria, the RHC provides important information for treatment decisions in the remaining patients.

Conflict of interest: M. Humbert reports receiving personal fees from Actelion Pharmaceuticals Ltd, United Therapeutics and Merck, and grants and personal fees from Bayer and GSK. J. Weatherald reports receiving grants from the European Respiratory Society and the Canadian Thoracic Society; and personal fees and nonfinancial support from Actelion Pharmaceuticals and Bayer, personal fees from Novartis, and grants from Canadian Vascular Network, outside the submitted work.

\section{References}

1 Galiè N, Humbert M, Vachiery J-L, et al. 2015 ESC/ERS Guidelines for the diagnosis and treatment of pulmonary hypertension. Eur Respir J 2015; 46: 903-975.

2 Galiè N, Humbert M, Vachiery J-L, et al. 2015 ESC/ERS Guidelines for the diagnosis and treatment of pulmonary hypertension. Eur Heart J 2016; 37: 67-119.

3 Boucly A, Weatherald J, Savale L, et al. Risk assessment, prognosis and guideline implementation in pulmonary arterial hypertension. Eur Respir J 2017; 50: 1700889.

4 Hoeper MM, Kramer T, Pan Z, et al. Mortality in pulmonary arterial hypertension: prediction by the 2015 European pulmonary hypertension guidelines risk stratification model. Eur Respir J 2017; 50: 1700740. 
5 Kylhammar D, Kjellström B, Hjalmarsson C, et al. A comprehensive risk stratification at early follow-up determines prognosis in pulmonary arterial hypertension. Eur Heart J 2017 in press [https://doi.org/10.1093/ eurheartj/ehx257].

6 Nickel N, Golpon H, Greer M, et al. The prognostic impact of follow-up assessments in patients with idiopathic pulmonary arterial hypertension. Eur Respir J 2012; 39: 589-596.

7 Galie N, Jansa P, Pulido T, et al. SERAPHIN haemodynamic substudy: the effect of the dual endothelin receptor antagonist macitentan on haemodynamic parameters and NT-proBNP levels and their association with disease progression in patients with pulmonary arterial hypertension. Eur Heart J 2017; 38: 1147-1155.

8 Weatherald J, Boucly A, Chemla D, et al. Prognostic value of follow-up hemodynamic variables after initial management in pulmonary arterial hypertension. Circulation 2018; 137: 693-704.

9 Rubin LJ. Assessing prognosis of pulmonary arterial hypertension in the therapeutic era: importance of serial hemodynamic measurements. Circulation 2018; 137: 705-706.

10 Hoeper MM, Pittrow D, Opitz C, et al. Risk assessment in pulmonary arterial hypertension. Eur Respir J 2018; 51: 1702606.

11 van Wolferen SA, Marcus JT, Boonstra A, et al. Prognostic value of right ventricular mass, volume, and function in idiopathic pulmonary arterial hypertension. Eur Heart J 2007; 28: 1250-1257.

12 Swift AJ, Capener D, Johns C, et al. Magnetic resonance imaging in the prognostic evaluation of patients with pulmonary arterial hypertension. Am J Respir Crit Care Med 2017; 196: 228-239.

13 Rich S, Dantzker DR, Ayres SM, et al. Primary pulmonary hypertension. A national prospective study. Ann Intern Med 1987; 107: 216-223.

14 Humbert $\mathrm{M}$, Sitbon $\mathrm{O}$, Chaouat $\mathrm{A}$, et al. Pulmonary arterial hypertension in France: results from a national registry. Am J Respir Crit Care Med 2006; 173: 1023-1030.

15 Poms AD, Turner M, Farber HW, et al. Comorbid conditions and outcomes in patients with pulmonary arterial hypertension: a REVEAL registry analysis. Chest 2013; 144: 169-176.

16 Hjalmarsson C, Rådegran G, Kylhammar D, et al. Impact of age and comorbidity on risk stratification in idiopathic pulmonary arterial hypertension. Eur Respir J 2018; 51: 1702310.

17 Fox BD, Shimony A, Langleben D, et al. High prevalence of occult left heart disease in scleroderma-pulmonary hypertension. Eur Respir J 2013; 42: 1083-1091.

18 Robbins IM, Hemnes AR, Pugh ME, et al. High prevalence of occult pulmonary venous hypertension revealed by fluid challenge in pulmonary hypertension. Circ Heart Fail 2014; 7: 116-122.

19 Hoeper MM, Lee SH, Voswinckel R, et al. Complications of right heart catheterization procedures in patients with pulmonary hypertension in experienced centers. J Am Coll Cardiol 2006; 48: 2546-2552. 